\title{
As perspectivas da felicidade na era digital: o caso brasileiro
}

\author{
The prospects of happiness in the digital age: the brazilian case \\ Las perspectivas de la felicidad en la era digital: el caso brasileño
}

Recebido: 18/11/2021 | Revisado: 24/11/2021 | Aceito: 25/11/2021 | Publicado: 07/12/2021

\author{
Honor de Almeida Neto \\ ORCID: https://orcid.org/0000-0002-5245-9441 \\ Universidade Luterana do Brasil, Brasil \\ E-mail: honorneto@terra.com.br \\ Everton Rodrigo Santos \\ ORCID: https://orcid.org/0000-0002-6270-3196 \\ Universidade FEEVALE, Brasil \\ E-mail: chabert89@gmail.com \\ Henrique Carlos de Oliveira Castro \\ ORCID: https://orcid.org/0000-0001-8976-838X \\ Universidade Federal do Rio Grande do Sul, Brasil \\ E-mail: henrique@ufrgs.br \\ José Antônio Ribeiro de Moura \\ ORCID: https://orcid.org/0000-0003-2316-4836 \\ Universidade FEEVALE, Brasil \\ E-mail: mourareis@uol.com.br
}

\begin{abstract}
Resumo
Este artigo tem como objetivo principal investigar o impacto das novas tecnologias de informação e comunicação nas relações humanas e sociais, no que tange ao sentimento de felicidade e de bem-estar subjetivo. Em outras palavras, procuramos demonstrar, como hipótese de trabalho, que há uma relação estreita entre as novas mediações sociais e a instauração de uma cultura mais autônoma e, portanto, de bem-estar, que está na gênese da Sociedade em Rede nesta Era Digital. Redes sociais constituem-se em uma plataforma digital que possibilita e potencializa a autocomunicação de massas, a sociabilidade, cuja prática tende a instaurar uma cultura ligada à autonomia e ao empoderamento, criando o processo de individuação. Os dados analisados de nossa pesquisa apontam que pessoas mais conectadas na rede tendem a ser mais felizes, nutrindo um sentimento de maior liberdade e autonomia. A base empírica deste artigo é a Sétima Onda da Pesquisa Mundial de Valores (WVS, 2017-2020), pesquisa quantitativa, tipo survey, que utilizaremos para demonstrar nosso argumento.
\end{abstract}

Palabras clave: Felicidade; Internet; Individuação; Sociedade em rede; Autocomunicação de massas.

\begin{abstract}
The main objective of this article is to investigate the impact of new information and communication technologies on human and social relations, with regard to the feeling of happiness and subjective well-being. In other words, we try to demonstrate, as a working hypothesis, that there is a close relationship between the new social mediations and the establishment of a more autonomous culture and, therefore, of well-being, which is in the genesis of the Network Society in this Digital Age. Social networks are a digital platform that enables and enhances mass selfcommunication, sociability, whose practice tends to establish a culture linked to autonomy and empowerment, creating the process of individuation. The data analyzed in our research show that people who are more connected to the network tend to be happier, nurturing a feeling of greater freedom and autonomy. The empirical basis of this article is the seventh wave of the World Values Survey (WVS, 2017-2020), a quantitative survey type survey, which we will use to demonstrate our argument.
\end{abstract}

Keywords: Happiness; Internet; Individuation; Network society; Mass self-communication.

\section{Resumen}

Este artículo tiene como objetivo investigar el impacto de las nuevas tecnologías de la información y la comunicación en las relaciones humanas y sociales, en lo que respecta al sentimiento de felicidad y bienestar subjetivo. Es decir, buscamos demostrar, como hipótesis de trabajo, que existe una estrecha relación entre las nuevas mediaciones sociales y el establecimiento de una cultura más autónoma y, por tanto, del bienestar, que está en la génesis de la Red. Sociedad en esta era digital. Las redes sociales constituyen una plataforma digital que posibilita y potencia la autocomunicación masiva, la sociabilidad, cuya práctica tiende a establecer una cultura ligada a la autonomía y al empoderamiento, generando el proceso de individuación. Los datos analizados de nuestra investigación muestran que las personas que están más conectadas a la red tienden a ser más felices, alimentando un sentimiento de mayor 
libertad y autonomía. La base empírica de este artículo es la Séptima Ola de la Encuesta Mundial de Valores (WVS, 2017-2020), una encuesta cuantitativa, que usaremos para demostrar nuestro argumento.

Palabras clave: Felicidad; Internet; Individuación; Sociedad red; Autocomunicación masiva.

\section{Introdução}

A história das relações humanas e da construção social dos fenômenos não podem ser desvinculadas da história das mediações sociais, das tecnologias disponíveis em cada período histórico, bem como das rupturas que essas mediações instauram nas sociedades, em todas as suas dimensões. Hoje, as novas mídias rompem com os limites de tempo e de espaço e complexificam a realidade, ao transformarem drasticamente a forma como produzem e transmitem as informações. Quanto às características dessas mídias, Pierre Levy aponta para três grandes categorias, um-todos, um-um e todos-todos. A imprensa, a televisão e o rádio são estruturados de acordo com o princípio um-todos: um centro emissor envia suas mensagens a um grande número de receptores passivos e dispersos. O correio ou o telefone organizam relações recíprocas entre interlocutores, mas apenas para contato indivíduo a indivíduo ou ponto a ponto, um-um (Levy, 1999). O advento das mídias interativas, como a Internet, trouxe de original para as relações sociais a maior possibilidade de conexão entre as pessoas, em tempo muitíssimo mais veloz e independente da distância, do espaço: [...] são os novos dispositivos informacionais e comunicacionais que são os maiores portadores de mutações culturais (Levy, 1999, p.63). Na comparação com as mediações anteriores, sobretudo a imprensa (escrita) e a televisão, a Internet é potencialmente transformadora, visto que a televisão e a imprensa podem impor uma visão da realidade e inibir a resposta, a crítica e o confronto entre posições divergentes. Em contrapartida, a diversidade das fontes e a discussão aberta são inerentes ao funcionamento de um ciberespaço que é incontrolável por essência (Levy, 1999). A Internet é um meio de comunicação que permite, pela primeira vez, a comunicação de muitos com muitos e em escala global e, assim como a difusão da máquina impressora no Ocidente criou o que MacLuhan chamou de a Galáxia de Gutenberg, ingressamos agora em um novo mundo de comunicação: a Galáxia da Internet (Castells, 2003).

É diante desse contexto que no campo acadêmico e, sobretudo, no âmbito das Ciências Sociais, o tema da felicidade tem sido objeto de debate em domínios como a satisfação com a vida, a saúde e as relações interpessoais, bem como as avaliações subjetivas sobre a sociedade. Esse novo ecossistema cognitivo (Levy, 1999) cria o processo de individuação ${ }^{1}$, ao trazer o indivíduo para o centro do cenário de produção das sociedades, o que potencializa a importância de sua avaliação sobre sua vida e sua felicidade. Assim, paralelo às condições objetivas que circundam os cidadãos, torna-se importante, no âmbito da opinião pública, mensurar a dimensão subjetiva de suas experiências cotidianas.

Neste sentido, o presente artigo objetiva investigar o impacto das novas mediações sociais nas relações humanas e sociais, no que tange ao sentimento de felicidade e de bem-estar subjetivo. Em outras palavras, procuramos demonstrar, como hipótese de trabalho, que há uma relação estreita entre as novas mediações sociais e a instauração de uma nova cultura, mais autônoma e, portanto, de bem-estar, que está na gênese da Sociedade em Rede, Era Digital. A base empírica deste artigo é a Sétima Onda da Pesquisa Mundial de Valores (WVS, 2017-2020), pesquisa quantitativa, tipo survey, que utilizaremos para demonstrar nosso argumento.

O artigo está subdividido em três partes que organizam e articulam nossa análise, tensionando nosso arcabouço teórico-epistemológico com nossa base empírica. No primeiro item, demonstraremos que as redes sociais, ao potencializar a sociabilidade e a autonomia comunicativa dos sujeitos, instauram felicidade e, também, a relação entre renda e felicidade no contexto da sociedade do consumo. No segundo item, analisaremos se há sintonia entre felicidade, autonomia e respeito à liberdade e à democracia. No terceiro item, discutiremos a importância da religião e da fé para a produção da felicidade e as

\footnotetext{
${ }^{1}$ Sociedade "Eu-centrada", declínio das formas tradicionais de comunidade (espaço, trabalho, família). Uma forma de comunidade, fundada nos interesses, valores e projetos individuais (Castells, 2015).
} 
mudanças em curso na função social da religião nesses tempos líquidos. Por fim, traremos as considerações finais com a indicação de tendências a esse fenômeno no Brasil, assim como as referências utilizadas como base nesta investigação.

\section{Metodologia}

A partir de uma perspectiva epistemológica associada ao racionalismo aplicado (Bachelard, 1985), e na esteira da tradição sociológica em pesquisas quantitativas, esse estudo tem como objetivo investigar o impacto das novas mediações sociais nas relações humanas e sociais, no que tange ao sentimento de felicidade e de bem-estar subjetivo. Procuramos demonstrar, como hipótese de trabalho, que há uma relação estreita entre as novas mediações sociais e a instauração de uma nova cultura, mais autônoma e, portanto, de bem-estar, que está na gênese da Sociedade em Rede, Era Digital.

O referencial teórico é alicerçado em autores da sociologia contemporânea, como Manuel Castells (Sociedade em rede/Sociologia da Comunicação); Zigmund Bauman (Sociedade líquido-moderna); Ronald Inglehart (Sociedades Pósmaterialistas); Ruut VEENHOVEN e Marita Carballo (Ciência da Felicidade).

A base empírica deste artigo é a Sétima Onda da Pesquisa Mundial de Valores (WVS, 2017-2020), pesquisa quantitativa, tipo survey, que utilizaremos para demonstrar nosso argumento cruzando as variáveis associadas a hipóteses a ser demonstrada. A base de dados é o Brasil. Como forma de qualificar ainda mais a análise, após a construção das tabelas, fruto do cruzamento de variáveis, aplicamos o Teste Qui Quadrado, que confirma a relação entre as elas. A base teórica que fundamenta esta metodologia de pesquisa quantitativa está fundamentada nas obras de Barbetta (2010) e Snedecor (1996).

\section{Resultados e Discussão}

\subsection{Felicidade em rede: sociabilidade e empoderamento}

Conforme os referenciais teóricos utilizados como filtros nesta investigação, há uma relação entre a percepção que as pessoas têm sobre sua felicidade e o acesso que têm à Internet, indicador contemporâneo de sociabilidade. A tabela 1, seguinte, apresenta essa relação:

Tabela 1 - Felicidade e Internet.

\begin{tabular}{lccccc}
\hline \multicolumn{5}{c}{ Fonte de informação: Internet } \\
\hline & Diariamente & Semanal & Por mês & $\begin{array}{c}\text { Menos que } \\
\text { mensalmente }\end{array}$ & Nunca \\
\hline Muito feliz & $29,2 \%$ & $30,4 \%$ & $27,7 \%$ & $25,7 \%$ & $24,6 \%$ \\
Bem feliz & $61,4 \%$ & $60,6 \%$ & $67,0 \%$ & $62,1 \%$ & $61,7 \%$ \\
Não muito feliz & $7,7 \%$ & $9,0 \%$ & $5,3 \%$ & $8,1 \%$ & $11,6 \%$ \\
Nem um pouco feliz & $0,5 \%$ & - & - & $1,2 \%$ & $1,3 \%$ \\
N/S & $1,1 \%$ & - & - & - & $0,5 \%$ \\
N/R & - & - & $100 \%$ & $100 \%$ & $0,4 \%$ \\
\hline TOTAL & $100 \%$ & $100 \%$ & & $100 \%$ \\
\hline
\end{tabular}

Fonte: WVS, $7^{\text {a }}$ Onda (2017-2020).

Analisando a Tabela 1, sempre os maiores índices de acesso à internet acompanham um maior sentimento de felicidade. Como exemplo disso, para quem acessa diariamente a internet, 29,2\% são "muito felizes" e 61,4\% são "bem felizes". Em contrapartida, apenas 7,7\% dos que acessam diariamente são "não muito felizes" e 0,5\% são "nem um pouco felizes". Já na outra ponta, daqueles que "nunca acessam a internet", os percentuais caem para 24,6\% de "muito felizes" e sofrem uma discreta variação de $61,7 \%$ de "bem feliz". Os "não muito felizes" sobem para $11,6 \%$ e "nem um pouco feliz", 
para 1,3\%. Porém, ao aplicarmos nesta tabela o teste Qui-quadrado, a partir da base de dados processados no SPSS, a correlação não se confirmou neste caso, o que, por outro lado, não invalida a tendência, como veremos a seguir.

Assim, quando relacionamos acesso às redes sociais e sentimento de liberdade e escolha, confirmamos essa tendência. Redes sociais constituem-se em uma plataforma digital que possibilita e potencializa a autocomunicação ${ }^{2}$ de massas, cuja prática tende a instaurar uma cultura ligada à autonomia ${ }^{3}$ e ao empoderamento, como demonstra a tabela a seguir:

Tabela 2 - Sentimento de felicidade e acesso às redes sociais.

\begin{tabular}{lccccc}
\hline \multicolumn{5}{c}{ Fonte de informação: redes sociais (Facebook, Twitter, etc.) } \\
\hline & Diariamente & Semanal & Por mês & $\begin{array}{c}\text { Menos que } \\
\text { mensalmente }\end{array}$ & Nunca \\
\hline Muito feliz & $29,5 \%$ & $30,0 \%$ & $25,7 \%$ & $31,5 \%$ & $24,4 \%$ \\
Bem feliz & $61,3 \%$ & $65,1 \%$ & $58,4 \%$ & $51,3 \%$ & $62,5 \%$ \\
Não muito feliz & $7,8 \%$ & $4,0 \%$ & $15,9 \%$ & $13,0 \%$ & $10,8 \%$ \\
Nem um pouco feliz & $0,3 \%$ & $0,9 \%$ & - & $1,2 \%$ & $1,3 \%$ \\
N/S & $1,0 \%$ & - & - & $-2,9 \%$ & $0,8 \%$ \\
N/R & $0,1 \%$ & - & $100 \%$ & $100 \%$ & $0,2 \%$ \\
\hline TOTAL & $100 \%$ & $100 \%$ & & - & $100 \%$ \\
\hline
\end{tabular}

Fonte: WVS, 7ª Onda (2017-2020).

Conforme observa-se na Tabela 2, quanto maior é a frequência de acesso das pessoas às redes sociais, mais aumenta o sentimento de felicidade, sendo que aqueles que acessam as redes sociais diariamente apresentam os maiores índices de respostas definindo-se como "muito feliz" (29,5\%) e "bem feliz" (61,3\%). Ao passo que há relação entre um sentimento de infelicidade e o pouco acesso à rede. De acordo com os dados da WVS, para aqueles que acessam diariamente as redes, apenas $7,8 \%$ se definem como "não muito feliz" e $0,3 \%$ se dizem "nem um pouco feliz". Na outra ponta, dentre aqueles que nunca acessam as redes sociais, o percentual cai para 24,4\% que se definem como "muito feliz" e 62,5\% como "bem feliz". Já o percentual dos que se dizem "não muito feliz" (10,8\%) e "nem um pouco feliz" (1,3\%) aumenta. Para verificarmos se de fato há uma associação entre as variáveis, aplicamos o teste Qui-quadrado, conforme Quadro 1, que confirma esta associação significativa:

Quadro 1 - Sentimento de felicidade e acesso às redes sociais.

\begin{tabular}{|l|c|c|c|}
\hline & Valor & gl & Significância Assintótica (Bilateral) \\
\hline Qui-quadrado de Pearson & $20,928^{\mathrm{a}}$ & 12 &, 051 \\
Razão de verossimilhança & 21,854 & 12 &, 039 \\
Associação Linear por & 10,739 & 1 &, 001 \\
Linear & 1713 & & \\
$\mathrm{~N}^{\circ}$ de Casos Válidos & & \\
\hline
\end{tabular}

a. 5 células $(25,0 \%)$ esperavam uma contagem menor que 5. A contagem mínima esperada é ,26. Fonte: Autores.

Nossa hipótese, com base em Castells (2015), é a de que ocorre uma mudança qualitativa na cultura da sociedade em rede, que influencia a percepção sobre a própria felicidade, pois “....a Internet, como todas as tecnologias, é cultura material, portanto incorpora uma construção cultural. No caso da Internet, a cultura é a da liberdade” (Castells, 2015, p. 35). Mas como

\footnotetext{
${ }^{2}$ A difusão da Internet gerou uma nova forma de comunicação interativa, e a capacidade de enviar mensagens de muitos para muitos, em tempo real ou no tempo escolhido, a autocomunicação de massa.

${ }^{3}$ A chave do processo de individuação é a construção da autonomia pelos atores sociais que definem seus projetos específicos em interação com as instituições da sociedade, mas sem se submeterem a elas.
} 
se dá essa relação entre acesso às redes e felicidade? Dentre as inúmeras rupturas associadas ao advento das novas mediações (sobretudo a Internet), que transformam radicalmente as relações humanas e sociais, é possível afirmar que o acesso à internet e às redes sociais digitais geram felicidade, ao introduzirem uma cultura de liberdade e autonomia, em oposição a uma cultura de passividade e controle, predominante antes do fenômeno da autocomunicação de massa. A internet traz felicidade, pois amplia duas áreas fundamentais para a felicidade: a sociabilidade e a autonomia/empoderamento. Há uma relação direta entre a ascensão da internet e a autonomia social. O uso da Internet parece estar promovendo a felicidade, visto que empodera as pessoas, aumentando sua sensação de segurança, liberdade pessoal e influência, todas estas percepções que têm um efeito positivo na felicidade e no bem-estar pessoal (Castells, 2015). Quanto à relação entre acesso às redes sociais e sentimento de liberdade e escolha, veja a tabela a seguir:

Tabela 3 - Sentimento de liberdade e acesso às redes sociais.

\begin{tabular}{lc}
\hline Frequência de Acessos & Quanta liberdade de escolha: se tem de 1 a 10 \\
\hline Diariamente & 5,2 \\
Semanalmente & 0,7 \\
Uma vez por mês & 0,1 \\
Menos que mensalmente & 0,4 \\
Nunca & 3,0 \\
N/S & 0,2 \\
\hline N/R & 0,07 \\
\hline
\end{tabular}

Fonte: WVS, $7^{\text {a }}$ Onda (2017-2020).

Observando-se os dados da Tabela 3, em que cruzamos a frequência no acesso às redes sociais com o sentimento de liberdade de escolha e controle que os indivíduos manifestam sobre suas vidas, numa escala de 1 a 10 (1= nenhum controle e $10=$ total controle), podemos constatar que aqueles que acessam diariamente as redes sociais, ou seja, os que mais acessam, têm uma pontuação média de 5,2. Este percentual cai para 0,7 com aqueles que acessam semanalmente; e cai mais ainda, $0,1 \mathrm{com}$ aqueles que acessam uma vez por mês. Aqueles que nunca acessam pontuam em 3,0. Quem acessa as redes sociais diariamente tem quase duas vezes mais chances de se sentirem mais livres e com controle sobre suas vidas do que aqueles que nunca acessam as redes. Quando aplicamos o teste Qui-quadrado, conforme Quadro 2, confirmamos que há de fato uma associação significativa entre o sentimento de liberdade e acesso às redes sociais.

Quadro 2 - Sentimento de liberdade e acesso às redes sociais

\begin{tabular}{|l|c|c|c|}
\hline & Valor & gl & Significância Assintótica (Bilateral) \\
\hline Qui-quadrado de Pearson & $75,338^{\mathrm{a}}$ & 36 &, 000 \\
Razão de verossimilhança & 75,822 & 36 &, 000 \\
Associação Linear por &, 908 & 1 &, 341 \\
Linear & 1691 & & \\
$N^{\text {o de Casos Válidos }}$ & & \\
\hline
\end{tabular}

a. 17 células $(34,0 \%)$ esperavam uma contagem menor que 5. A contagem mínima esperada é ,32. Fonte: dos autores 
Outro indicador de empoderamento e de autonomia dos indivíduos está associado à preferência por lançar um olhar predominantemente científico sobre as questões e conflitos sociais, em detrimento de um olhar religioso. A atuação nas redes sociais é diretamente proporcional à preferência pela ciência em detrimento da religião, como demonstra a tabela a seguir:

Tabela 4 - Fonte de informação e ciência x religião.

\begin{tabular}{lcccc}
\hline \multicolumn{4}{c}{ Sempre que a ciência e a religião entram em conflito, a religião está sempre certa. } \\
\hline $\begin{array}{c}\text { Concordo } \\
\text { plenamente }\end{array}$ & Aceita & Discordo & Discordo fortemente \\
\hline Diariamente & $33,2 \%$ & $50,9 \%$ & $55,7 \%$ & $63,9 \%$ \\
Semanal & $3,5 \%$ & $6,5 \%$ & $6,4 \%$ & $3,9 \%$ \\
Por mês & $2,5 \%$ & $1,2 \%$ & $2,6 \%$ & $0,0 \%$ \\
Menos que mensalmente & $4,0 \%$ & $4,0 \%$ & $4,8 \%$ & $3,2 \%$ \\
Nunca & $56,8 \%$ & $37,5 \%$ & $30,5 \%$ & $29,0 \%$ \\
\hline Total & $100 \%$ & $100 \%$ & $100 \%$ & $100 \%$ \\
\hline
\end{tabular}

Fonte: WVS, $7^{\mathrm{a}}$ Onda (2017-2020).

$\mathrm{Na}$ Tabela 4, daquelas pessoas que se posicionaram em relação à frase "sempre que a ciência e a religião entram em conflito, a religião está sempre certa”, 33,2\% que concordam plenamente com a frase, acessam diariamente a internet. Por outro lado, aquelas pessoas que discordam fortemente de que "sempre que a ciência e a religião entram em conflito, a religião está sempre certa", 63,9\% acessam a internet. Assim, esses internautas que "discordam fortemente" da primazia da religião frente à ciência são os mesmos que acessam "diariamente" as redes. O maior índice dos que "concordam plenamente" em favor da religião (56,8\%), não por acaso, está na faixa daqueles que "nunca” acessam as redes sociais. Quanto mais constante é a presença no universo on-line, mais afirmada é a ciência em detrimento da religião. Cabe reforçar aqui que a ciência e o conhecimento científico são conquistas da humanidade e um grande passo para a autonomia e independência dos homens frente à natureza, frente ao "poder divino" e, sobretudo, frente a outros homens. Portanto, um olhar com base na realidade que leve minimamente em conta o conhecimento científico é um indicador de maior autonomia e liberdade em oposição à primazia de um viés religioso ${ }^{4}$. Aplicamos o teste Qui-quadrado, para verificarmos se de fato há uma associação significativa entre as variáveis, conforme o Quadro 3, e esta associação se confirmou.

Quadro 3 - Fonte de informação e ciência x religião.

\begin{tabular}{|c|c|c|c|}
\hline & Valor & gl & Significância Assintótica (Bilateral) \\
\hline $\begin{array}{l}\text { Qui-quadrado de Pearson } \\
\text { Razão de verossimilhança } \\
\text { Associação Linear por Linear } \\
\mathrm{N}^{\circ} \text { de Casos Válidos }\end{array}$ & $\begin{array}{c}63,427^{\mathrm{a}} \\
65,194 \\
43,800 \\
1541\end{array}$ & $\begin{array}{c}12 \\
12 \\
1\end{array}$ & $\begin{array}{l}, 000 \\
, 000 \\
, 000\end{array}$ \\
\hline
\end{tabular}

a. 2 células $(10,0 \%)$ esperavam uma contagem menor que 5. A contagem mínima esperada é 3,02. Fonte: Autores.

${ }^{4}$ Essa relação entre religiosidade e felicidade, muito presente na sociedade brasileira, fatalista e familista, será abordada posteriormente neste artigo. 
Outro aspecto que precisamos considerar é que, em se tratando de uma sociedade do consumo ${ }^{5}$, sociedade líquidomoderna (Bauman, 2010), há evidentemente uma certa relação entre renda e acesso a bens de consumo e sentimento de felicidade.

Tabela 5 - Sentimento de felicidade e nível de renda.

\begin{tabular}{lcccc}
\hline \multicolumn{4}{c}{ Nível de renda (recodificado) } & \\
\hline & Baixo & Médio & Alto & Não sei \\
\hline Muito feliz & $24,2 \%$ & $28,8 \%$ & $37,3 \%$ & $29,7 \%$ \\
Bem feliz & $62,8 \%$ & $61,5 \%$ & $52,4 \%$ & $63,5 \%$ \\
Não muito feliz & $10,8 \%$ & $8,3 \%$ & $6,7 \%$ & $5,6 \%$ \\
Nem um pouco feliz & $1,2 \%$ & $0,5 \%$ & - & $1,2 \%$ \\
N/S & $0,6 \%$ & $1,0 \%$ & - & - \\
N/R & $0,3 \%$ & - & $100 \%$ & $100 \%$ \\
\hline Total & $100 \%$ & $100 \%$ & - & - \\
\hline
\end{tabular}

Fonte: WVS, $7^{\mathrm{a}}$ Onda (2017-2020).

A felicidade está na renda alta. Os números corroboram essa correlação, pois os maiores índices de respostas que se auto definem como "muito feliz" e "bem feliz" (90,3\%) estão na "Renda Média", e "muito feliz" e "bem feliz" (89,7\%) estão na faixa de "Renda Alta". O menor índice de "muito feliz" e bem feliz" (86,4\%) está na faixa "renda baixa", como podemos observar na Tabela 5. Aliás, ninguém da faixa de "renda alta" definiu-se como "nem um pouco feliz". O maior índice de "Não muito feliz" $(10,8 \%)$ e o de "Nenhum pouco feliz" (1,2\%), não por acaso, está na faixa de "renda baixa". Novamente, aplicando-se o teste Qui-quadrado, conforme Quadro 4, confirmamos a associação significativa entre as variáveis renda e felicidade.

Quadro 4 - Sentimento de felicidade e nível de renda.

\begin{tabular}{|l|c|c|c|}
\hline & Valor & $\mathrm{gl}$ & Significância Assintótica (Bilateral) \\
\hline Qui-quadrado de Pearson & $61,321^{\mathrm{a}}$ & 36 &, 005 \\
Razão de verossimilhança & 65,513 & 36 &, 002 \\
Associação Linear por & 2,023 & 1 &, 155 \\
Linear & 1648 & & \\
$\mathrm{~N}^{\circ}$ de Casos Válidos & & \\
\hline
\end{tabular}

a. 19 células $(38,0 \%)$ esperavam uma contagem menor que 5. A contagem mínima esperada é ,06. Fonte: Autores.

No contexto do capitalismo, aquilo que o dinheiro não satisfaz, poucas outras coisas satisfarão. Na sociedade de consumidores, vivemos uma vida líquida, e a vida líquida é uma vida de consumo, ela projeta o mundo e seus habitantes como objetos de consumo. Em uma sociedade regida pelo mercado, cada desejo tem um preço afixado, não se pode ter coisas, a não ser comprando-as (Bauman, 2009). Assim, "numa sociedade do consumo, os caminhos são muitos e diversos, mas todos eles levam às lojas; a busca pela dignidade, autoestima e de felicidade exige a mediação do mercado" (Bauman, 2009, p.140). Em análise recente, já em um contexto de Pandemia de COVID 19, Morin (2020), aponta que a sociedade do consumo, "põe o consumidor na dependência do produtor, e pode dar ao consumidor, se emancipado, poder sobre o produtor. Essa nova consciência aquisitiva, o período do isolamento nos mostrou até que ponto é possível e necessária”. (Morin 2020, p.27).

\footnotetext{
${ }^{5}$ A articulação entre globalização e individualismo leva à difusão do consumismo, forma individual de relação com um processo de globalização dominado pela expansão do capitalismo (Castells, 2015).
} 
Porém, há limites para essa relação entre felicidade e renda, pois, para as pessoas que têm atendidas essas necessidades básicas, materialistas (Inglehart, 1977), abrem-se novas demandas. Em contextos pós-materialistas, por exemplo, incidirão também valores de auto expressão, pois o aumento do poder aquisitivo não se correlaciona linearmente com um incremento significativo nos níveis de felicidade (Veenhoven, 1991). Em complemento a essa abordagem, as análises confirmam que mais dinheiro aumenta a felicidade, até certo nível, mas que valores pós-materialistas, que dependem da relação com outras pessoas, aumentam ainda mais a probabilidade da felicidade e satisfação com a vida. A "verdadeira" felicidade pode ser encontrada em sociedades desenhadas institucional e culturalmente para a autorrealização e autonomia dos cidadãos. Esta realização pode ser profissional, nas relações de amizade ou familiares (Lane, 2000). Em complemento a esse pensamento, Diener (1996) afirma que aqueles que conseguem nomear vários amigos próximos são mais saudáveis e mais prováveis de viver por mais tempo. Diener (1999) e Seligman (2011) também detectaram que cada uma das pessoas muito felizes do seu estudo empírico tinha excelentes relações sociais, análise que está em sintonia com a perspectiva de Castells (2015) de que a sociabilidade incide diretamente sobre o sentimento de felicidade.

Conforme Bauman, "num ambiente líquido, imprevisível e de fluxo rápido, precisamos de laços firmes e seguros de amizade e confiança mútua (Bauman, 2009, p.140). O acesso às redes, ao potencializar o compartilhamento e a sociabilidade, incide novamente sobre a percepção de felicidade das pessoas, pois, ao contrário do que aponta o senso comum, as pessoas hoje, com base em seus dispositivos móveis, viajam mais, encontram-se mais, interagem mais, compartilham mais e tornam-se potencialmente mais autônomas, como demonstra a tabela a seguir, que articula as variáveis felicidade e fontes de informação (sociabilidade on line):

Tabela 6 - Fonte de informação, amigos e felicidade.

\begin{tabular}{lcccc}
\hline \multicolumn{4}{c}{ Importante na vida: Amigos [sentimento de felicidade = muito feliz] } \\
\hline & Muito importante & Bastante importante & $\begin{array}{c}\text { Não muito } \\
\text { importante }\end{array}$ & Nada importante \\
\hline Diariamente & $52,3 \%$ & $61,6 \%$ & $39,5 \%$ & - \\
Semanal & $9,5 \%$ & $4,6 \%$ & $3,6 \%$ & - \\
Por mês & $1,4 \%$ & $2,1 \%$ & - & $17,7 \%$ \\
Menos que mensalmente & $5,2 \%$ & $4,7 \%$ & $4,3 \%$ & - \\
Nunca & $29,5 \%$ & $25,3 \%$ & $2,3 \%$ \\
N/S & - & $1,3 \%$ & $1,8 \%$ & - \\
N/R & $2,0 \%$ & $0,4 \%$ & $100 \%$ & $100 \%$ \\
\hline Total & $100 \%$ & $100 \%$ & $2,3 \%$ & - \\
\hline
\end{tabular}

Fonte: WVS, $7^{\mathrm{a}}$ Onda (2017-2020).

Analisando a Tabela 6, constata-se que quanto maior a frequência dos índices de atuação e conexão com as redes sociais, maior a importância conferida às amizades e maiores também os índices de felicidade. Daqueles que consideram "muito importante" em suas vidas os amigos, $52,3 \%$ acessam diariamente as redes sociais e se consideram "muito feliz", ao passo que esse índice cai drasticamente para 1,4\% para quem acessa mensalmente a internet. No outro extremo da tabela, chama a atenção para aqueles que, mesmo muito felizes, não consideram "nada importante" em suas vidas os amigos. Desta forma, $82,3 \%$ destes "nunca acessam" as redes. Interessante observar que ninguém que acessa "diariamente ou semanalmente" as redes sociais considera "nada importante" em suas vidas os amigos.

A seguir, no Quadro 5, o Qui-quadrado demonstrou associação significativa entre as variáveis. 
Quadro 5 - Fonte de informação, amigos e felicidade.

\begin{tabular}{|l|c|c|c|}
\hline & Valor & Gl & Significância Assintótica (Bilateral) \\
\hline Qui-quadrado de Pearson & $27,593^{\mathrm{a}}$ & 12 &, 006 \\
Razão de verossimilhança & 28,360 & 12 &, 005 \\
Associação Linear por Linear & 12,636 & 1 &, 000 \\
$\mathrm{~N}^{\circ}$ de Casos Válidos & 1727 & & \\
\hline
\end{tabular}

a. 4 células $(20,0 \%)$ esperavam uma contagem menor que 5. A contagem mínima esperada é ,87. Fonte: Autores.

Há também uma estreita relação entre o sentimento de liberdade e a felicidade e quanto mais acesso as pessoas têm às redes, maior a tendência de internalização de uma cultura de liberdade, que é inerente ao ciberespaço.

Tabela 7 - Felicidade e liberdade de escolha.

\begin{tabular}{lc}
\hline & Quanto à Liberdade de Escolha e Felicidade: se tem de 1 a 10 \\
\hline Muito Feliz & 2,5 \\
Bem Feliz & 5.8 \\
Não Muito Feliz & 0,1 \\
Nem um Pouco Feliz & 0,4 \\
N/S & 0,2 \\
N/R & 0,1 \\
\hline
\end{tabular}

Fonte: WVS, $7^{\mathrm{a}}$ Onda (2017-2020).

Se cruzarmos os índices de liberdade de escolha e felicidade, teremos as médias apresentadas na tabela acima. Observando-se os dados da Tabela 7, numa escala de 1 a 10 (1= não é um bom negócio e 10= um bom negócio à liberdade de escolha), podemos constatar que aqueles que se consideram "muito feliz" têm uma pontuação média de 2,5. Este percentual sobe para 5,8 para os que se consideram "bem feliz", cai drasticamente para 0,1 dentre os que consideram "não muito feliz", e 0.4 para os que se auto definem como "nem um pouco feliz". É possível intuir, com base nesses números, que quanto maior a importância atribuída a fatores como a liberdade e o controle sobre suas vidas, maior é o sentimento de felicidade. O aumento da liberdade acompanha o aumento da felicidade. Agrupando os dados, na "felicidade" (muito feliz e bem feliz), temos um índice médio de apreço à liberdade e ao controle de 8,3, ao passo que na "infelicidade" (não muito feliz e nem um pouco feliz), quanto ao apreço ao controle sobre a sua vida e à liberdade, somam apenas 0.5.Na medida em que nos deslocamos da esquerda para a direita na Tabela 7, ou seja, de mais valorização da liberdade e controle, para menos valorização de liberdade e controle, os mais infelizes vão se fazendo mais presentes proporcionalmente. O teste ilustrado abaixo comprovou essa associação significativa:

Quadro 6 - Felicidade e liberdade de escolha.

\begin{tabular}{|l|c|c|c|}
\hline & Valor & Gl & Significância Assintótica (Bilateral) \\
\hline Qui-quadrado de Pearson & $78,433^{\mathrm{a}}$ & 27 &, 000 \\
Razão de verossimilhança & 69,671 & 27 &, 000 \\
Associação Linear por Linear & 19,890 & 1 &, 000 \\
$\mathrm{~N}^{\mathbf{o}}$ de Casos Válidos & 1702 & & \\
\hline
\end{tabular}

a. 13 células $(32,5 \%)$ esperavam uma contagem menor que 5. A contagem mínima esperada é ,14. Fonte: Autores.

O processo de autocomunicação de massas, que rompe com um modelo de comunicação passiva, instaura uma cultura de liberdade, aumenta a sensação de autonomia e de liberdade. É um modo de comunicação caracterizado pela considerável autonomia dos sujeitos comunicantes em relação aos donos e reguladores da infraestrutura de comunicação. Isso acontece porque as tecnologias de redes digitais permitem que indivíduos e organizações gerem seus próprios conteúdos e mensagens e 
os distribuam no ciberespaço, evitando amplamente o controle de corporações e burocracias (Castells, 2015). Esse empoderamento associado à autocomunicação de massas tem um efeito particularmente positivo em pessoas de baixa renda e poucas qualificações, para pessoas nos países em desenvolvimento e para as mulheres.

Nossa análise está embasada no pressuposto epistêmico, que indica ser papel do pesquisador instaurar-se na descontinuidade e nas rupturas dos fenômenos, como forma de indicar tendências e escapar ao risco de dizer o óbvio e reproduzir o senso comum com status de ciência (Bourdieu, 1990). Nesta perspectiva, observa-se um paradoxo na discussão que articula autonomia e empoderamento com a percepção sobre felicidade. Estamos nós, indivíduos contemporâneos, expostos a uma visibilidade nunca antes experimentada, frente ao fim dos limites de tempo e de espaço que caracterizam a Sociedade em Rede. A dinâmica da sociedade do consumo e dos consumidores transforma todos os seus indivíduos em objetos de consumo, em produtos. Todos somos alvos de monitoramento e manipulação constante, a partir de algoritmos que fornecemos, registros (rastros) das informações que disponibilizamos sobre nós mesmos na rede, relativas a aspectos como: predileção de consumo, opinião política ou expressão geral de valores e percepções. E, embora esse processo aumente o controle, de forma paradoxalmente contraditória, complementar e antagônica ${ }^{6}$, observa-se que o espaço virtual é um lugar ainda não totalmente controlado e dominado nem pelo mercado e nem pelo Estado. Espaço que potencializa uma maior autonomia comunicativa aos indivíduos, onde as informações (fontes primárias de exercício e manutenção do poder) circulam de uma forma mais livre. Ocorre que "o acesso à informação ainda é desigual em favor das empresas e em desfavor dos consumidores, mas estes já não estão tão vulneráveis à manipulação e ao controle da propaganda, como estavam antes do advento dessas tecnologias" (Abranches, 2017). A ausência de controle é a essência da Internet, e o controle sempre teve historicamente relacionado ao domínio e monopólio da informação (antes unidimensional), fonte histórica de exercício e manutenção do poder através de diversas formas de violência simbólica e, por isso, a luta pelo poder é a batalha pela construção de significados na mente das pessoas (Castells, 2013).

\subsection{Felicidade e democracia}

Se a autonomia é uma condição geradora de felicidade, espera-se que haja uma sintonia entre felicidade, autonomia e respeito à liberdade e à democracia. Serão as pessoas mais felizes também as mais democráticas? E, de outro lado, serão as pessoas mais autoritárias também as mais infelizes?

Na literatura sobre capital social, há evidências de que uma sociedade democrática possui impactos positivos sobre a felicidade (Frey \& Stutzer, 2012). Isso ocorre porque, quando as pessoas se sentem incluídas no processo de tomada de decisão, elas são mais felizes. O espírito democrático constitui-se em um importante indicador de autonomia e de empoderamento. Como demonstra a tabela a seguir:

Tabela 8 - Felicidade e espírito democrático.

\begin{tabular}{lc}
\hline & Quanto à importância da democracia: se tem de 1 a 10 \\
\hline Muito Feliz & 2,8 \\
Bem Feliz & 6,2 \\
Não Muito Feliz & 0,8 \\
Nem um Pouco Feliz & 0,1 \\
N/S & 0,1 \\
N/R & 0 \\
\hline
\end{tabular}

Fonte: WVS, 7 $7^{\mathrm{a}}$ Onda (2017-2020).

\footnotetext{
${ }^{6}$ Um olhar complexo sobre o real, rompe com o cartesianismo e o maniqueísmo, que não contempla o convívio entre os contrários. Aqui, os fenômenos se contrapõem, se complementam e entram em conflito.
} 
Quando examinamos os dados da Tabela 8, numa escala de 1 a 10 (1= nada importante à democracia e $10=$ muito importante à democracia), podemos constatar que, para os do que se declaram "muito feliz", a média ficou em 2,8; e, entre os "bem felizes", aumentou para 6,2. Ao passo que, dentre os "não muito felizes", a pontuação cai de forma acentuada para 0,8; e, dentre os "nem um pouco feliz", 0,1 e "não sei”, 0,1 .

É possível intuir, com base nesses índices, que quanto maior a importância atribuída à democracia, maior é o sentimento de felicidade. Agrupando os dados, a "felicidade" tem um índice médio de apreço à democracia de 9.0, e, no outro extremo, a "infelicidade" soma apenas 0.9 de média de apreço à democracia.

No item a seguir, discutiremos brevemente uma outra variável que incide sobre a percepção sobre a felicidade e que é muito presente no caso brasileiro aqui em tela: a religiosidade. Por outro lado, se levarmos em conta o fato de vivermos em tempos líquidos, em que a incerteza e a imprevisibilidade estão na base das relações sociais, e "prever tendências futuras, a partir de eventos passados torna-se cada dia mais arriscado e, frequentemente, enganoso", pois "em suma a vida líquida é uma vida precária, vivida em condições de incerteza constante (Bauman, 2009), será a religião uma instituição importante na produção da felicidade? Serão as pessoas mais religiosas também as mais felizes?

\subsection{Felicidade e fé}

Diante da riqueza e complexidade dos dados disponibilizados pelo WVS, inúmeras são as relações possíveis entre variáveis para subsidiar as análises e, embora não seja um objetivo deste artigo aprofundar a relação entre a religiosidade e o sentimento de felicidade, faremos de forma sucinta essa aproximação, sobretudo pela importância e aplicabilidade da análise da felicidade no caso brasileiro, país extremamente religioso:

Tabela 9 - Religiosidade no Brasil.

\begin{tabular}{lc}
\hline & Importância da Religião \\
\hline Muito importante & $\%$ \\
Bastante importante & $45,1 \%$ \\
Não muito importante & $39,5 \%$ \\
Nada importante & $10,4 \%$ \\
N/S & $4,7 \%$ \\
N/R & $0,2 \%$ \\
Total & $0,2 \%$ \\
\hline
\end{tabular}

Fonte: WVS, $7^{\text {a }}$ Onda (2017-2020).

Para quase $90 \%$ da população brasileira, a religião é importante, daí também os altos índices de felicidade no país, mesmo em um cenário historicamente marcado por uma imensa exclusão social, violência e preconceitos de toda ordem. Conforme Ellison (1991), o envolvimento com atividades religiosas está positivamente correlacionado à felicidade. A religião ofereceria uma chave interpretativa que pode ajudar a dar sentido à vida, além de uma característica relacional que captura a integração dos indivíduos nas comunidades a que pertencem. Aqui o componente da sociabilidade e mesmo o capital social estão associados à participação em comunidades religiosas.

Segundo o World Happiness Report (2019), no período de 2016 a 2019, o Brasil caiu no ranking de felicidade do $17^{\circ}$ para o $32^{\circ}$ lugar, perdendo na escala 6,3 pontos. Essa diminuição talvez explique a opção da população na eleição por um governo com um viés político tão antagônico de governos anteriores. Esse período e os últimos anos do governo que o antecederam foram tempos marcados por retração no crescimento econômico e na distribuição de renda no país, aumento dos 
índices de desemprego, diminuição de gastos públicos e, sobretudo, do ponto de vista político, um período fortemente marcado por severas críticas aos governantes, protestos e escândalos de corrupção, que desencantaram boa parte do eleitorado brasileiro com a política e com a democracia, promovendo uma guinada brusca à extrema direita no país, com um discurso de desconstrução da política e da democracia, com forte apelo moral e religioso. Uma direção escolhida por aqueles que sabem que o sentimento de religiosidade está intimamente relacionado com o sentimento de felicidade.

Tabela 10 - Felicidade e religiosidade: o caso brasileiro.

\begin{tabular}{lcccc}
\hline & \multicolumn{2}{c}{ Importância da Religião } \\
\hline \multicolumn{2}{c}{$\begin{array}{c}\text { Muito } \\
\text { Importante }\end{array}$} & $\begin{array}{c}\text { Bastante } \\
\text { Importante }\end{array}$ & Não muito importante & Nada importante \\
\hline Muito Felizes & $34,4 \%$ & $22,2 \%$ & $23,0 \%$ & $23,7 \%$ \\
Bem Felizes & $56,8 \%$ & $66,7 \%$ & $62,7 \%$ & $56,2 \%$ \\
Não muito & $7,9 \%$ & $9,3 \%$ & $11,6 \%$ & $12,2 \%$ \\
Nem um pouco & $0,6 \%$ & $1,0 \%$ & $1,0 \%$ & - \\
N/S & $0,3 \%$ & $0,6 \%$ & $1,8 \%$ & $6,7 \%$ \\
N/R & - & $0,1 \%$ & - & $1,2 \%$ \\
& $100 \%$ & $100 \%$ & $100 \%$ & $100 \%$ \\
\hline
\end{tabular}

Fonte: WVS, $7^{\mathrm{a}}$ Onda (2017-2020).

Examinando a Tabela 10, podemos observar que, dentre os que consideram a religião "muito importante", 91,2 \% são “muito felizes" e "bem felizes". Apenas 8,5\% disseram-se "não muito felizes" e "nem um pouco feliz". Da esquerda para a direita, na medida em que diminui a importância atribuída à religião, diminui a felicidade. Na ponta direita da tabela, do grupo de pessoas que disseram que a religião é nada importante, o percentual de felizes cai para 79,9\% que se dizem "muito feliz" e “bem feliz". Já o percentual sobe para 12,2\% daqueles "não muito feliz" e "nem um pouco feliz". O teste Qui-quadrado corrobora essa associação significativa entre religião e felicidade:

Quadro 7 - Felicidade e religiosidade: o caso brasileiro

\begin{tabular}{|c|c|c|c|}
\hline & Valor & $\mathrm{gl}$ & Significância Assintótica (Bilateral) \\
\hline Qui-quadrado de Pearson & $32,800^{\mathrm{a}}$ & 9 &, 000 \\
Razão de verossimilhança & 33,060 & 9 &, 000 \\
Associação Linear por Linear & 16,360 & 1 &, 000 \\
$\mathrm{~N}^{\circ}$ de Casos Válidos & 1738 & & \\
\hline
\end{tabular}

a. 2 células (12,5\%) esperavam uma contagem menor que 5. A contagem mínima esperada é ,60. Fonte: Autores.

Em síntese, pessoas com religiosidade e fé são mais felizes do que aquelas não religiosas num primeiro momento. Esse é o caso de uma parcela significativa da população brasileira. Se cruzarmos esses dados com a pesquisa realizada por Almeida (2007), que analisa os valores dos brasileiros, este demonstra que há uma relação direta entre o nível de escolaridade, por exemplo, e valores concebidos por ele como arcaicos. Dentre esses valores arcaicos, a violência como forma de resolução de conflitos, a negação da democracia, o machismo, a confiança apenas na família (familismo), baixos índices de capital social, dentre outros, caracterizam a cultura brasileira. Podemos destacar aqui o fatalismo, típico de países como o Brasil, onde temos uma sociedade pouco escolarizada, cuja visão dominante entre a população é a de que Deus decide o destino dos homens, ou seja, a autonomia dos indivíduos está limitada pelo destino. Essa constatação talvez explique os altos índices de felicidade que ainda temos no Brasil, apesar da alta desigualdade social e pobreza. 
Todavia, muito embora o Brasil ainda seja um país religioso e feliz, tanto a felicidade quanto a religiosidade, curiosamente, vêm declinando. Em estudo recente, com base nos dados da sétima onda do WVS, Inglehart (2020) analisa 49 países no mundo e constata que em 43 deles, entre os anos de 2007/2019, se tornaram menos religiosos, tais como: a Espanha, os Estados Unidos, o Reino Unido, a Finlândia, a Suécia, inclusive o Brasil, entre outros. Há um processo de secularização em curso. Entretanto, este processo não se deve somente ao desenvolvimento econômico e tecnológico, mas sobretudo, segundo o autor, às mudanças nas normas de fertilidade humana. No contexto de sociedades agrárias, por exemplo, em que os níveis de mortalidade infantil eram altos, somados às baixas expectativas de vida, a religião que encoraja a produção de crianças e desencoraja o aborto, o divórcio, a contracepção e a homossexualidade, certamente tem um papel necessário aí (Inglehart, 2020). Contudo, quando o desenvolvimento amplia as capacidades humanas de existência, há gradativamente a supressão da mortalidade infantil, da fome, da morte prematura, e as pessoas se tornam "menos dependentes da religião - e menos dispostos a aceitar suas restrições, incluindo manter mulheres na cozinha e gays no armário"7 (Inglehart, 2020, p. 114). Desta forma, a religião perde terreno.

Se esta análise estiver correta, gradativa e lentamente, a religião deixa de ser uma fonte de produção de sentido e de felicidade em sociedades que começam a transitar para contextos pós-materialistas, pois elas têm perdido sua função social. Será que a internet, as redes sociais, essas novas formas de mediações serão capazes de suprir a necessidade de felicidade e de autonomia de forma persistente? Dito de outra forma, serão as novas mediações capazes de reconectar os seres humanos consigo mesmos de forma secular?

\section{Considerações Finais}

Com base na empiria disponibilizada pelos dados da WVS, e a partir de um olhar teórico associado às Ciências Sociais Contemporâneas, e que, logo, considera como central o impacto da tecnologia para a construção social (em um modelo de análise sócio técnica do real), foi possível demonstrar neste artigo que a felicidade é potencializada pela nova dinâmica comunicacional que cria o processo de individuação e transforma os meios, fluxos e estratégias de comunicação e, portanto, as relações de poder. Nesse contexto, a felicidade dos indivíduos está intimamente associada a aspectos como o exponencial aumento da sociabilidade presencial e, sobretudo, on-line, que instaura uma cultura mais autônoma e mais associada à liberdade e empoderamento dos indivíduos, confirmando nossa hipótese de pesquisa.

Longe de expressar um contexto de condição material resolvida, grande parcela da sociedade brasileira apresenta níveis baixos de escolaridade e taxas preocupantes de analfabetismo funcional, possui ainda acentuada concentração de renda e transita entre um Estado que oferta serviços públicos de baixa qualidade e é insuficiente garantidor do Estado de direito. Os cidadãos brasileiros, em perspectiva ampliada, estão cada vez mais inseridos no processo de globalização, e, de maneira incongruente, absorvem os diversos valores trazidos a reboque desse processo.

No caso específico brasileiro, fatores como a extrema desigualdade econômica e social, a alta religiosidade, a baixa escolarização e o desigual processo de inclusão digital, incidem sobre a percepção de felicidade, como podemos demonstrar. Na sociedade dos consumidores, há uma estreita relação entre felicidade e capacidade de compra. A busca pela felicidade tem na sociedade da informação e do conhecimento, num contexto de uma sociedade em rede, novas configurações e novas perspectivas. Podemos apontar como tendência, com base na empiria analisada, que o aumento da percepção de felicidade dos indivíduos está associado também a uma maior distribuição de renda e acesso a bens e serviços por parte das camadas mais pobres da população, uma maior inclusão digital, bem como o aprofundamento da democracia e da participação política no país.

${ }^{7}$ Traduzido por: tradutor google - Bing. https://www.bing.com. Consultado em 05/03/2021. 
Nesta perspectiva, o controle da comunicação e da informação que constitui a fonte histórica do exercício do poder e da dominação, é hoje muito mais disputada, tensionada com diferentes atores, do que era em épocas pretéritas. Neste sentido, estes novos tensionamentos e novas configurações podem potencializar o aprofundamento da democracia no país ou não. Isto vai depender da forma como vamos processar institucionalmente estas novas relações entre Estado e sociedade. Não é coincidência, portanto, que, neste início de século XXI, se discute o direito à privacidade de dados e de informações dos mais de 7 bilhões de cidadãos do planeta como um direito humano fundamental. Os índices de satisfação com a vida e com a democracia, sobretudo, vem caindo conforme Santos (2001), e esse desgaste vem abrindo espaço para o fenômeno atual da judicialização da política e do ativismo do judiciário.

A base teórica utilizada nesta investigação, bem como o banco de dados da WVS (atualizado de quatro em quatro anos), permitem o cruzamento de dados de inúmeras variáveis, para além das utilizadas nesta pesquisa. Assim, também a possibilidade de comparação entre países indica que inúmeros outros artigos serão produzidos nesta temática. A ciência da felicidade aborda um tema atual, dinâmico e de interesse de todos, da população e dos governos de maneira geral e do campo acadêmico em particular. E novas pesquisas sobre o tema estão por vir e serão produzidas por este grupo de pesquisadores que apresentou este artigo.

\section{Referências}

Abranches, S. (2017). A Era do Imprevisto: a grande transição do século XXI. Companhia das Letras.

Almeida, C. A. (2007). A cabeça do brasileiro. Ed Record.

Barbetta, P. A. (2010). Estatística aplicada as Ciências Sociais. Ed. UFSC.

Bauman, Z. (2010). Modernidade Líquida. Editora Jorge Zahar.

Bauman, Z. (2009). Vida Líquida. Zahar.

Carballo, M. (2021). La Felicidade de Las Naciones: claves para um mundo melhor. Argentina, Ed. Sudamericana, https://ler.amazon.com.br/?asin=b00u497qj0.

Castells, M. (2015). O Poder da Informação. Paz e Terra.

Castells, M. (2013). Redes de Indignação e Esperança: Movimentos Sociais na Era da Internet. Zahar.

Castells, M. (2004). A Sociedade em Rede. Paz e Terra, 1, (6a.ed.).

Castells, M. (2003) A galáxia da Internet: reflexões sobre a Internet, os negócios e a sociedade. Jorge Zahar.

Bachelard, G. (1985). O novo espírito científico. Tempo Brasileiro.

Bourdieu, P. (1999). Razões Práticas. Papirus.

Diener, E., Suh, E. M., Lucas, R. E., \& Smith, H. L. (1999). Subjective well- being: Three decades of progress. Psychological Bulletin, 125.

Ellison, C. G. (1991). Religious involvement and subjective well-being. Journal of Health and Social Behavior.

Frey, B., \& Stutzer, (2012). A. The use of happiness research for public policy. Social Choice and Welfare, 38(4), 659-674.

Inglehart, R. (2000). Modernización y Posmodernizacion. El Cambio cultural, econômico y politico en 43 sociedades. Siglo XXI. Madrid.

Inglehart, R., \& Welzel, C. (2009). Modernização, mudança cultural e democracia: e sequencia do desenvolvimento humano. Francis.

Inglehart, R., \& Welzel, C.; (2012). A Revolução Silenciosa na Europa: Mudança Intergeracional nas Sociedades Pós-Industriais. Revista de Sociologia e Política, 20(43), 159-191.

Inglehart, R., \& Welzel, C. (1977). The Silent Revolution. Princeton University Press.

Inglehart, R., \& Welzel, C. (2020). Giving Up on God. The Global Decline of Religion. Foreign Affairs. 99(5). 110/118.

Lane, R. E. (2000). The Loss of Happiness in Market Democracies. Yale University Press.

Levy, P. (1999). Cibercultura. Ed. 34. 
Research, Society and Development, v. 10, n. 16, e95101623518, 2021

(CC BY 4.0) | ISSN 2525-3409 | DOI: http://dx.doi.org/10.33448/rsd-v10i16.23518

Morin, E. (2020). É hora de mudarmos de via: as lições do coronavírus. Tradução de Ivone Castilho Benedetti.: Bertrand Brasil, 97 p.

Pesquisa Mundial de Valores. (2020), http://www.worldvaluessurvey.org/WVSOnline.jsp.

Rennó, L. (2001). Confiança Interpessoal e Comportamento Político: microfundamentos da teoria do capital social na América Latina. Campinas, SP: Opinião Pública, 7(1),.33-59.

Rennó, L. (2015). Corrupção, cultura política e capital social negativo no Brasil. Revista Debates, 2(9), 139-157.

Rennó, L. (2007). Democracia e capital social na américa latina: uma análise comparativa. Curitiba, PR: Revista Sociologia Política., (28), $221-234$.

Santos. E. R. (2021). Ciência Política: lições sobre o jogo do poder. Ijuí, RS: Ed. Unijuí.

Seligman. M. (2002). Authentic happiness: Using the new Positive Psycology to realize your potencial for lasting fulfillment. London: Nicholas Brealey Publishing.

Sen, A. (2000). Desenvolvimento como liberdade. Cia das Letras.

Snedecor, G. W., Cochran, W. G. (1996). Statistical methods. (5a ed.), Ames: Iowa State University Press, 503 p.

Veenhoven, R. (1991). Questions on happiness: Classical topics, modern answers, blind spots. In: F. Strack, M. Argyle, \& N. Schwarz (Eds.), Subjective wellbeing: An interdisciplinary perspective, p. 7-26. Oxford, England: Pergamon Press, 1991, repub.eur.n1/pub/16149/91c-full.pdf $>$.

World Happiness Report. (2020). Online data analysis, 2019, https://worldhappiness.report. 